\title{
Occupational stress, job satisfaction and job involvement amongst organizational employees
}

\author{
Nilesh Thakre ${ }^{1}$ Padmini Barua ${ }^{2}$ \\ ${ }^{1}$ Associate Professor, Department of Psychology, SNDT University, Mumbai. \\ ${ }^{2}$ Life Skill Counselor, Assam Valley School, Assam. \\ E-mail - thakre_nilesh@rediffmail.com
}

\begin{abstract}
Background : The current century is a world of stress and has become a regular aspect of human life. The amount of knowledge on the concept of stress and its effects on organizational work life are growing in all directions. This study investigates the differences between employees with high occupational stress and employees with low occupational stress on job satisfaction and job involvement.

Methodology : The participants of the study constitute 60 employees working in corporate organization. They were assessed by using occupational stress index, job attitude scale and job involvement scale. An independent-samples t-test was conducted to compare differences among individuals with high occupational stress and low occupational stress.

Results : The study revealed a significant difference between employees with high occupational stress and low occupational stress, on job satisfaction, $\mathrm{t}(58)=5.96, \mathrm{p}<0.05$ and on job involvement $\mathrm{t}(58)=2.44$, $\mathrm{p}<0.05$. The findings indicate that employees with low occupational stress scored higher on job satisfaction and job involvement than employees with high occupational stress.

Conclusions : These suggest that the level of occupational stress in an employee does have an impact on his/her job involvement and job satisfaction. This trend will enable organizations to acknowledge the needs of lower occupational stress at work place.
\end{abstract}

Keywords: Occupational stress, Job satisfaction, Job involvement, Organizational Employees

\section{INTRODUCTION}

We can say that the current century is a world of stress and has become a regular aspect of human life. The amount of knowledge on the concept of stress and its effects on organizational work life are growing in all directions. The forever growing needs and ambitions, competition, weakened social support, pressure of meeting deadlines and uncertainty of future have made life very much challenging and highly stressful. Various research papers focus on studying occupation stress and its impact on work life of an employee in almost all organizations [1]. Various studies have found significant relationship between occupational stress and job satisfaction [2-4]. For many people, a great deal of stressful events stem from the workplace.

Occupational stress has two major dimensions - physiological stress and psychological stress. Physiological stress is often viewed as a physiological reaction of the body (headache, migraine, abdominal pain, lethargic, backache, chest pain, fatigue, heart palpitation, sleep disturbance and muscle ache, as well as changes in eating, drinking, sleeping and smoking habits) to various stressful triggers at the workplace [5]. Stressors at the individual level have been studied more than any other category. Role conflicts, role ambiguity, role overload and under load, is widely examined individual 
stressors [6]. It is also reported by many researchers that the low job satisfaction was associated with high stress [4]. Brewer [7] examined the relationship between job stress and job satisfaction. Correlation analysis revealed significant differences in the correlations between job satisfaction and frequency of stressors and correlations between job satisfaction and intensity of stressors, suggesting that frequency of stressors had a greater impact on participants' job satisfaction. Similarly, other researchers, while investigating the effect of age on occupational stress and job satisfaction among managers found that the high occupational stress results in significant low job satisfaction [8]. Job satisfaction has been identified as a key indicator of employee well-being and a predictor of employee physical and mental health [9-11].

Authors have examined the impact of job characteristics and job involvement on correctional staff job stress. Specifically, the effects of supervision, perceived dangerousness of the job, job variety, feedback, role stress, and job involvement were studied, while controlling for the effects of the personal characteristics of gender, educational level, race, age, and tenure. Using Ordinary Least Squared regression, it was observed that gender, age, perceived dangerousness of the job, feedback, role stress, and job involvement had statistically significant effects on correctional staff job stress. Tenure, educational level, race, supervision, and job variety had non-significant effects [12].

Others have studied the causal relationship among the job uncertainty, job involvement, job stress, and job performance of banking service personnel under the economic depression. Three hundred and sixty-three effective surveys were received from banking service personnel. The data were analyzed by reliability analysis, exploratory factor analysis, confirmatory factor analysis, using the structural equation model to measure the relationship among the constructs. The empirical results found that job stress has a positive influence on job involvement and job performance. The mediating effects of job stress and job involvement can positively influence job performance [13].

Chen analyzed the mechanism of role stress impacting on job involvement. The theoretical framework is developed to deduce the relationship among role stress, job involvement and organizational commitment as a mediate variable. Based on more than 300 questionnaires of Zhejiang enterprises, the impact of role stress on job involvement is studied by using regression analysis. The research results show that role stress will lead employee to reduce organizational commitment and job involvement of the staff, however, organizational commitment is needed to enhance staff input [14].

In a recent empirical study on the impact of occupational stress among teachers on job satisfaction and job involvement, it was concluded that the variables in occupational stress have considerable impact on some variables of job satisfaction and job involvement of employees. Stress can be reduced when the above variables are addressed. Here the researcher does not say that the job satisfaction and job involvement can be measured only by variables of occupational stress index; there are some other variables to measure job satisfaction and job involvement. Finally the researcher concludes that there is a considerable level of impact of stress on job satisfaction and job involvement among teachers [15].

The present study examines how implicit attitudes towards one's organisation, supervisor, and co-workers combine with explicit job satisfaction measures to better predict job involvement.

Hypotheses for the current study -

1. There is a significant difference between employees with high occupational stress and low occupational stress on job satisfaction.

2. There is a significant difference between employees with high occupational stress and low occupational stress on job involvement.

\section{METHODOLOGY}

The participants of the present study consisted of 60 employees working in corporate organizations. The age range of the participants was 28 to 33 years. All the participants belonged to similar socio-economic status and were from the city of Mumbai. Purposive convenient sampling technique was used. The data was analyzed by using t-test where appropriate. 
The tools used in the study for assessment were -

1. Occupational Stress Index - The occupational stress was measured by using occupational stress index [16]. This scale was administered to assess the level of stress among the employees. The scale consists of 46 items, each to be rated on a five-point scale. Out of 46 items, 28 are 'true' keyed and the balance 18 is 'false' keyed. The scale measures the extent of employees' perceived stress arising from various constituents and conditions of their job. The items measures job overload, role ambiguity, role conflict, group and political pressure, responsibility for persons, under participation, powerlessness, poor peer relations, intrinsic impoverishment, low status, strenuous working conditions and unprofitability were included. The reliability index ascertained by split half (odd-even) method and Cronbach's alpha co-efficient for the scale as a whole were found to be 0.94 and 0.90 respectively. The validity of the OSI was determined by computing coefficient of correlation between the scores on OSI and various measures of job attitudes and behaviour and they were found to be sufficiently high.

2. Job Attitude Scale - The job satisfaction of employees is assessed by using job attitude scale developed by Srivastava [17]. The inventory to assess the employees' liking (satisfaction) and disliking (dissatisfaction) for various aspects of their job such as job activities, work conditions, social relations, security, compensation, etc. The statements in the questionnaire also represents positive/negative attitude towards different dimensions of work. The questionnaire comprises of 15 true-keyed items. Homogeneity index of the items ranged from 0.38 to 0.58 . Split-half reliability of the scale was found to be 0.79 . Validity of the scale has been established against the measures of job stress, $(r=0.294, p>0.05)$, job performance $(r=0.201, p>0.01, n=300)$, and psychological well-being $(\mathrm{r}=0.414, \mathrm{p}>0.01, \mathrm{n}=300)$.

3. Job Involvement Scale - It is a short measure of employees' involvement in their jobs. The scale consists of 15 true-keyed items to be rated on 4- point scale by the employees to indicate the extent to which each item stands true or false in describing their own feelings about, commitment to, and ego involvement in their jobs. Internal consistency of the scale was ascertained by computing homogeneity index of the items comprising it. The obtained indices ranged from 0.46 to 0.69 . Split-half reliability indices of the scale were found to 0.95 . The validity of the tool was further established by correlating its score with the scores on the measure job satisfaction. The obtained coefficient $(r=0.502)$ was found to be highly significant [18].

The human resource (HR) managers of corporate organizations were approached for data collection in the year 2014. They were provided with general nature of the study and confidentiality of result was assured. Although the organizations gave permission for data collection, not many participants were willing to fill up the questionnaire. Thus, total 100 employees were approached with permission from these organizations. Based on their willingness to participate in the study, 76 out of the initial 100 individuals who were approached gave their written consent for participation in study. However, those who responded with incomplete questionnaires had to be discarded. The final turnover of responses, after excluding the incomplete responses, was 60 . The scales were scored and individuals with high occupational stress were separated from those who scored low in occupational stress. The completed questionnaires were collected. After collection of data; verification, scoring, tabulation and analysis were done.

\section{RESULTS AND DISCUSSION}

Occupational stress is an extensively researched area that includes the study of related concepts such as absenteeism, turnover, performance, job satisfaction, job involvement, life satisfaction, motivation, burnout, conflict, aggression. The present study examines the difference between occupational stress (high or low) on job attitude and job involvement with the help of occupational stress index, job attitude scale and job involvement scale. The findings of the present study about occupational stress, job satisfaction and job involvement are as follows - 
Hypothesis 1 of the study stated that 'there is a significant difference between employees with high occupational stress and low occupational stress on job satisfaction' for testing this hypothesis $t$ test was conducted. The mean scores obtained by individuals with high occupational stress and low occupational stress on job satisfaction were compared by using $t$-test for the independent sample. The results of the descriptive statistics of the means and standard deviations are shown in Table 1 and Table 2 shows the results of t-test for job satisfaction and results of the descriptive statistics of the means and standard deviations are shown in Table 3 and Table 4 shows the results of t-test for job involvement respectively.

Table 1 - Mean and SD Values for Job Satisfaction

\begin{tabular}{|ccccc|}
\hline Organizational Stress & $\mathrm{N}$ & Mean & SD & SEM \\
\hline High & 30 & 31.47 & 6.47 & 1.18 \\
\hline Low & 30 & 41.43 & 6.46 & 1.18 \\
\hline
\end{tabular}

Table 2 - $t$ values for Job Satisfaction

\begin{tabular}{ccccc|}
\hline$t-$ Value & df & Significant & Mean diff & Std. Error \\
\hline $5.96^{*}$ & 58 & 0.00 & 9.96 & 1.67 \\
& & & \\
& & & \\
& &
\end{tabular}

It can be seen from Table -1, that the employees with high occupational stress scored lower $(M=31.47)$ than the employees with low occupational stress $(M=41.473)$ on job satisfaction. This shows that employees with high occupational stress are less satisfied than employees with low occupational stress. Analysis of data using t-test (Table 2) showed significant difference between employees with high occupational stress and employees with low occupational stress, $\mathrm{t}(58)=5.967, \mathrm{p}<$ 0.05 on job satisfaction. The scale score range was 15-61. The higher the score in the measure, the higher was the satisfaction in employees. This depicts that employees with low occupational stress are more satisfied with their job. Thus, hypothesis 1 is accepted.

A strikingly significant difference was found between employees with high occupational stress and employees with low occupational stress on job satisfaction. Employees with high occupational stress scored low on job satisfaction, whereas employees with low occupational scored high on job satisfaction. It is important to note here that job satisfaction is defined as "the extent of employees' liking (satisfaction) and disliking (dissatisfaction) for various aspects of their job such as job activities, work conditions, social relations, security, compensation, etc." Accordingly, the statements in the questionnaire also represents positive/negative attitude towards different dimensions of work and high scores indicated high satisfaction.

The increase in research on occupational stress, especially during the last decade has clearly established that job-related stress has an adverse impact on work related variables and specifically on job satisfaction. Studies on occupational stress highlights influence of that occupational stress on the organizational activities and it includes job satisfaction of employees and found significant relationship between occupational stress and job satisfaction [2-4]. The negative characteristics of jobs, not only create stressful emotional, mental and physical state within the work setting, but also create stressful conditions in the non- working life. These negative or stressful job characteristics could result in both negative work outcomes. Subsequently, same results were replicated [19-20]. In the light of the results of the present study, a distinctive difference can be seen in the mean of employees with high occupational stress and the mean of employees with low occupational stress. The mean of employees with high occupational stress was lower than the mean of employees with low occupational stress. This indicates that high occupational stress is associated with low satisfaction. Conversely, low occupational stress is associated with high satisfaction. Hence, it can be observed that an inverse relation between occupational stress and job attitude. Although such a directional relation was not predicted, the difference in mean indicate that occupational stress has a negative effect on job attitude. This holds true in most cases because when people are in jobs where there are no additional pressures, when one is clear 
about the work to be done, when interpersonal relationships with colleagues are cordial, then they are likely to be satisfied. Hence, the findings of the present study are in line with current researches that have shown that there is a difference in job satisfaction of employees with occupational stress.

Hypothesis 2 of the study stated that, "there is a significant difference between employees with high occupational stress and low occupational stress on job involvement." for testing this hypothesis $t$ test was conducted. The mean scores obtained by individuals with high occupational stress and low occupational stress on job involvement were compared by using $t$-test for the independent sample.

Table 3 - Mean and SD Values for Job Involvement

\begin{tabular}{|ccccc|}
\hline Occupational Stress & $\mathrm{N}$ & Mean & SD & SEM \\
\hline High & 30 & 35.13 & 4.73 & .86 \\
\hline Low & 30 & 38.63 & 6.26 & 1.14 \\
\hline
\end{tabular}

Table 4 - $t$ values for Job Involvement

\begin{tabular}{ccccc|}
\hline $\mathrm{t}-$ Value & Df & Significant & Mean diff & Std. Error \\
\hline $2.44^{*}$ & 58 & 0.01 & 3.50 & 1.43 \\
& \multicolumn{4}{c}{$* 0.05$ significant at .05 level }
\end{tabular}

It can be seen from Table -3, that the employees with high occupational stress scored lower $(M=35.13)$ than the employees with low occupational stress $(M=38.63)$ on job involvement. This shows that employees with high occupational stress are less involved in their work than employees with low occupational stress. Analysis of data using t-test (Table 4) showed significant difference between employees with high occupational stress and employees with low occupational stress, $\mathrm{t}(58)=2.442, \mathrm{p}<.05$ on job involvement. This depicts that employees with low occupational stress are more involved in their job. Thus, hypothesis 2 is accepted.

A significant difference was found between employees with high occupational stress and employees with low occupational stress on job involvement. Employees with high occupational stress scored low on job involvement, whereas employees with low occupational stress scored high on job involvement. In the present study, job involvement is defined as "the extent to which an employee feels committed towards his/her job". Accordingly, the statements in the questionnaire asked the employees to indicate the extent to which each item stands true or false in describing their own feelings about, commitment to, and ego involvement in their job and high scores indicated high involvement. Some studies reported relation with role overload, role conflict, role stress, burnout, the effects of supervision [6,12]. In the light of the results of the present study, a distinctive difference can be seen in the mean of employees with high occupational stress and the mean of employees with low occupational stress on job involvement. The mean of employees with high occupational stress was lower than the mean of employees with low occupational stress. This indicates that high occupational stress is associated with low involvement. The difference in mean indicate that job stress has a negative effect on job involvement. Those who are not involved do not look forward to their jobs; they work in jobs they care little about. Further, employees alienated from the job find it frustrating to attend work, day after day, which ultimately leads to increased job stress. Conversely, people who identify psychologically with their jobs may look forward to work. Hence, the findings of the present study are in line with the current researches that have shown that there is a difference in job involvement of employees with occupational stress.

\section{CONCLUSIONS}

The comprehensive findings of the present study report a significant relation between occupational stress, job attitude and job involvement. The important phenomenon of the effect of stress on job attitude and job involvement will enable organizations to acknowledge and sensitize them to 
the needs of employees' at work place. Hence, the findings of the present study contribute in strengthening the belief that the level of occupational stress in an employee does have an impact on his/her favourable and unfavourable attitude towards job and involvement.

Identification of issues related to occupational stress and its impact on other work- related variables, such as the ones studied in the present research, can have important implications for early and precise diagnosis such as burnout in employees, tendency to leave job, or decreased productivity. Depending on the severity of the problem, early and effective interventions can be made. Organizations should intervene to reduce occupational stress among employees in order to increase job satisfaction and job involvement.

\section{REFERENCES}

1. Karasek RA, Theorell T. Healthy work : Productivity and the reconstruction of working life. Basic Books : New York; 1990.

2. Keller RT. Role conflict and ambiguity : correlates with job satisfaction and values. Personnel Psychol 1975;28(1):57-64.

3. Abdul Halim AA. Social support and managerial affective responses to job stress. J Occup Behav 1982;3:281-95.

4. Leigh JH, Lucas GH, Woodman RW. Effects of perceived organizational factors on role stress-job attitude relationships. J Management 1988;14(1):41-58.

5. Antoniou AS, Polychroni F, Vlachakis AN. Gender and age differences in occupational stress and professional burnout between primary and high-school teachers in Greece. J Manage Psychol 2006;21(7):682-90.

6. Thakre N. Life orientation and organizational role stress among retail employees. BVIMR Management Edge 2009;2(2):77-82.

7. Brewer EW, McMahan-Landers J. Job Satisfaction among Industrial and Technical Teacher Educators. J Industr Teacher Educn 2003;40(2):65-85.

8. Rao JV, Chandraiah K. Occupational stress, mental health and coping among information technology professionals. Indian J Occup Environ Med 2012;16(1):22-6.

9. Cooper CL, Cartwright S. Healthy mind; healthy organization-A proactive approach to occupational stress. Hum Relat 1994;47(4):455-71.

10. Cooper CL, Kirkcaldy BD, Brown J. A model of job stress and physical health: The role of individual differences. Personal Individ Diff 1994;16(4):653-5.

11. Williams S, Cooper CL. Measuring occupational stress: development of the pressure management indicator. J Occup Health Psychol 1998;3(4):306-21.

12. Lambert EG, Hogan NL, Cluse-Tolar T. This job is killing me: The impact of job characteristics on correctional staff job stress. Appl Psychol Crim Justice 2007;3(2):117-42.

13. Ouyang $Y$. The mediating effects of job stress and job involvement under job instability: Banking service personnel of Taiwan as an example. J Money Invest Bank 2009;11:16-26.

14. Chen S. The relationship between role stress and job involvement-An empirical research of Zhejiang private enterprise. In Electronics, Communications and Control (ICECC), 2011 International Conference on 2011 Sep 9 (pp. 3414-3418).

15. Muthuvelayutham C, Mohanasundaram H. A study on the impact of occupational stress among teachers on Job satisfaction and job involvement-an empirical study. Eur J Soc Sci 2012;30(2):339-51.

16. Srivastava AK, Singh AP. Construction and standardization of an occupational stress index; a pilot study. Indian Journal of Clinical Psychology 1981;8:133-6.

17. Srivastava AK. Self-management of occupational stress: Cognitive-behavioural approach. Indian Journal of Industrial Relations 1997;32:487-95.

18. Srivastava AK, Singh AP. Manual of the Occupational stress Index, Department of Psychology, Banaras University, Varanasi ; 1981.

19. Richardsen AM, Burke RJ. Occupational stress and job satisfaction among physicians: Sex differences. Soc Sci Med 1991;33(10):1179-87.

20. Mansoor M, Fida S, Nasir S, Ahmad Z. The impact of job stress on employee job satisfaction a study on telecommunication sector of Pakistan. J Business Stud Quart 2011;2(3):50-6. 